\title{
Exchange rate's effects on optimal strategy of assembly supply chain
}

\author{
Chen Chao Ma Yong-kai
}

School of Management and Economics, University of Electronic Science and Technology of China

\begin{abstract}
Based on an assembly supply chain consisting of multiple complementary component suppliers and one manufacturer, we study what effects does exchange rate have on the decision-making and profit of the enterprises in the assembly supply chain through constructing a game model. The results show that the manufacture's optimal order quantity and every enterprise's profit will increase with the increase of expected exchange rate. This illustrates the manufacturer should increase order quantity if successfully forecast the raise of exchange rate, and all the enterprises in the supply chain will benefit from the behavior .
\end{abstract}

Keywords: assembly supply chain; exchange rate; game model

\section{Introduction}

With the process of economic globalization and Chinese market's opening, domestic enterprises are facing with more intense competition from around the world. To satisfy new requirements, more and more enterprises choose to take the foreign market into consideration during the process of purchase and sales. The strategy of supply chain globalization mentioned above enable enterprises gain competitive advantage one hand, however at the same time, it bring some risks on the other hand, such as exchange rate uncertain. None of enterprises choose to omit the factor of exchange rate in global supply chain management. It is significant to clarify what effects does the exchange rate have on enterprises in supply chain and make right decisions.

Several studies examined the effects of exchange rate on supply chain. $\mathrm{Ni}$ et al. (2013) investigated transmission of demand risk and exchange rate risk along the supply chain and how they affect node company. Ma and Shen (2004) studied how to make decisions for SMEs based on exchange rate in supply chain. Zhao (2012) examined what effects does exchange rate have on the parameters of supply chain contract and profit. Yang (2012) investigated how does the exchange rate affect the stability of supply chain, and established a coordination mechanism. Kouvelis and Axarloglou (2001) studied the effects of exchange rate's fluctuation on decisions of production. Shapiro (2005) propose that enterprises should take effective measure to avoid risks such as fluctuation of exchange rate.

The studies mentioned above pay attention to the exchange rate's effects on the supply chain, however none of them introduce the exchange rate into study of assembly supply chain. In contrast, some scholars studied the decision-making in assembly supply chain while without concerning the factor of exchange rate. For instance, Wang (2006) focused on the enterprises' decisions of yield and price in assembly supply chain. Guarnani and Gerchak (2007) studied the coordination 
of assembly supply chain with produce uncertainty.

\section{Model}

Concern a assembly supply chain with two component suppliers and one manufacturer. supplier 1 is native enterprise and supplier 2 is foreign enterprise ,both of which are risk-neutral.

The unit cost of component supplier $i$

( $i=1,2$ ) is $c_{i}$, without loss of generality, assume assembly proportion of suppliers is $1: 1$, The unit cost of manufacture is $c_{0}$, market price is 1 , demand of market is $D . D$ is a random variable with probability density function $f(x)$. The CCDF of $D$ is $F(x)$, which is continuously differentiable.

These two suppliers and the manufacturer realize their gains through contract of wholesale price. Each supplier give the wholesale price to manufacturer simultaneously (the price of component $i$ is $w_{i}$ ) and then the manufacturer decide the order quantity $q$ based on the sum of wholesale prices $\left(W=w_{1}+w_{2}\right)$. The whole process describe as the Fig. 1.

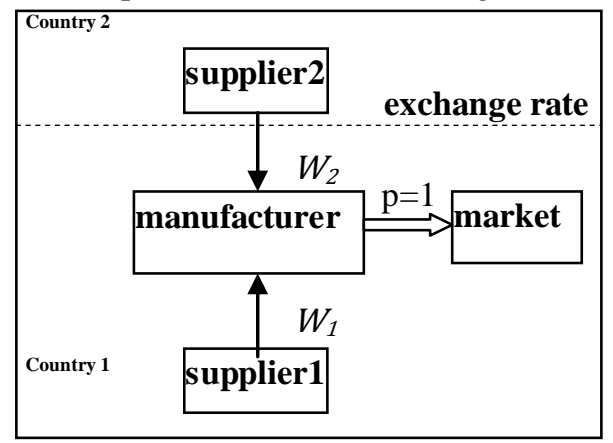
above.

Fig.1. assembly supply chain mentioned

According to the above description, the expected profit of supplier 1 is

$$
E\left(\pi_{1}\right)=\left(w_{1}-c_{1}\right) q
$$

The profit expression of supplier 2 is

$$
\pi_{2}=\left(\alpha_{t} w_{2}-\overline{c_{2}}\right) q
$$

$\overline{c_{2}}$ is the unit cost of supplier 2, which is calculated in the currency of supplier 2's country. The exchange rate between the countries of supplier 2 and manufacturer is $\alpha_{0}$ at present. Thus, $\overline{c_{2}}=\alpha_{0} c_{2}, c_{2}$ is the unit cost of supplier 2 which is calculated in currency of manufacturer's country. $\alpha_{t}$ is the exchange rate between countries of supplier 2 and manufacturer in the future. Suppose $\alpha_{t}=\alpha_{0}(1+r)$, $\alpha_{t} r$ is the change rate of the exchange rate, $E\left(\alpha_{\mathrm{t}}\right)=\eta_{\mathrm{t}}(1+\mu), \mu$ is the expectation of $r$.

$$
\text { Then } E\left(\pi_{2}\right)=\left(\eta_{t} w_{2}-\overline{c_{2}}\right) q
$$

Expected profit of manufacturer is

$$
\begin{aligned}
E\left(\pi_{0}\right) & =E(\min \{q, D\})-\left(W+c_{0}\right) q \\
& =\int_{0}^{q} 1-F(x) d x-\left(W+c_{0}\right) q
\end{aligned}
$$

$W=w_{1}+w_{2}, \quad c_{0}$ is the unit cost of manufacturer. From (4), we know that the optimal order quantity satisfies the equation

$$
1-F(q)=W+c_{0} \text {, which is first- }
$$
order condition .

\section{The solution of model}

\section{Proposition 1 :}

$\pi_{i}$ is concave function of $w_{i}(i=1,2)$ if $\frac{f(q) q}{1-F(q)}$ is the increasing function of $q$.

Proof: from (3), taking the first derivative of $E\left(\pi_{2}\right)$ with respect to $q$. $\frac{d E\left(\pi_{2}\right)}{d q}=\eta_{t}[1-F(q)]\left[1-\frac{f(q) q}{1-F(q)}\right]-\left(\eta_{t} w_{1}+\eta_{t} c_{0}+\overline{c_{2}}\right) \mathrm{S}$ ince $\frac{f(q) q}{1-F(q)}$ is the increasing function of $q$, existing $q_{1}>0$ meet the equation 
$\frac{f\left(q_{1}\right) q_{1}}{1-F\left(q_{1}\right)}=1$. Therefore, when $q>q_{1}$, $\frac{d E\left(\pi_{2}\right)}{d q}<0$; when $q<q_{1}, \frac{d E\left(\pi_{2}\right)}{d q}$ is the decreasing function of $q$, when $q=0$.we can obtain the expression

$$
\frac{d E\left(\pi_{2}\right)}{d q}=
$$

$\eta_{t}\left(1-w_{1}-c_{0}-\frac{\overline{c_{2}}}{\eta_{t}}\right)>\eta_{t}\left(1-w_{1}-c_{0}-w_{2}\right)>0$

So that, the expected profit of supplier 2 is the concave function of $q$, in fact, since $q$ is a decreasing function of $w_{2}$, thus the expected profit of supplier 2 is concave function of $w_{2}$ (the proof is similar for supplier 1).

According to Nash existence theorem, proposition 1 ensure the existing of pure strategy which meets Nash equilibrium , Nash equilibrium solution is expressed as $\left(w_{1}^{*}, w_{2}^{*}\right)$

From (1) and (3),taking the first derivative of $E\left(\pi_{i}\right)$ with respect to $w_{i}$ separately, we obtain first-order conditions (5) and (6). The equilibrium whole sale price $\left(w_{1}^{*}, w_{2}^{*}\right)$ meet first-order conditions.

$$
\begin{gathered}
\frac{d E\left(\pi_{1}\right)}{d w_{1}}=q-\frac{w_{1}-c_{1}}{f(q)}=0 \\
\frac{d E\left(\pi_{2}\right)}{d w_{2}}=\eta_{t} q-\frac{\eta_{t} w_{2}-\overline{c_{2}}}{f(q)}=0
\end{gathered}
$$

Combining $\quad 1-F(q)=W+c_{0} \quad$ with equation (5) and (6) we can obtain the manufactures optimal order quantity $q^{*}$ which satisfy the equations:

$2 \eta_{t} f\left(q^{*}\right) q^{*}-\eta_{t} W+\eta_{t} c_{1}+\overline{c_{2}}=0$ and

$$
\left[1-F\left(q^{*}\right)\right]\left[1-\frac{2 f\left(q^{*}\right) q^{*}}{1-F\left(q^{*}\right)}\right]=c_{0}+c_{1}+\frac{\overline{c_{2}}}{\eta_{t}}(7)
$$

If $\frac{f(q) q}{1-F(q)}$ is the increasing function of $q$, the $q^{*}$ in equation ( 7 ) can be proved to be unique and $q^{*}<q_{1}$. The proof is similar with the proposition 1 。

\section{Proposition 2 :}

The optical order quantity is increasing as the increasing of $\mu$.

it is easy to get the above conclusion from (7).

From (5) and (6),we can know the uniqueness of $q^{*}$ ensure that balanced wholesale price $\left(w_{1}^{*}, w_{2}^{*}\right)$ is unique.

$$
\begin{aligned}
& w_{1}^{*}=\frac{c_{1}}{c_{2}}+q^{*} f\left(q^{*}\right) \\
& w_{2}^{*}=\frac{c_{2}}{\eta_{t}}+q^{*} f\left(q^{*}\right)
\end{aligned}
$$

Combining ( 8 ) and (9) with (1) and (3), we obtain the follow equation.

$$
E\left(\pi_{i}^{*}\right)=\left(q^{*}\right)^{2} f\left(q^{*}\right)
$$

Equation (10) implies different suppliers have the same expectated profit. This conclusion correspond to existing papers.

it is noted that, $E\left(\pi_{2}\right)$ in (10) is calculated in currency of manufacturer's country. When calculated in the currency of supplier 2's country , we obtain

$$
E\left(\pi_{2}\right)=\eta_{t}\left(q^{*}\right)^{2} f\left(q^{*}\right)
$$

\section{Proposition 3 :}

Suppliers' expected profit increases with the increase of $\mu$.

\section{Proof:}

Let $u(q)=q^{2} f(q), s(q)=\frac{q f(q)}{1-F(q)}$,

$t(q)=q[1-F(q)] \quad, \quad$ since 
$\frac{d t(q)}{d q}=[1-F(q)]\left[1-\frac{q f(q)}{1-F(q)}\right], \quad$ this implies when $q<q_{1}, t(q)$ is the increasing function of $q, s(q)$ is the increasing function of $q$.Thus, when $q<q_{1}$, $u(q)=s(q) t(q)$ is the increasing function of $q$. Combining the above conclusions with proposition 2 , we can obtain proposition 3.

\section{Proposition 4:}

The manufacturer's expected profit increases with the increase of $\mu$.

Proof: from (4) we can obtain $\frac{d E\left(\pi_{0}\right)}{d q}=1-F(q)-\frac{d W}{d q} q-\left(W+c_{0}\right)=-f(q) q<0$

the above expression implies that the manufacturer's expected profit increase with the decrease of optimal order quantity. Combining the above conclusion with proposition 2 , we obtain proposition 4.

\section{Conclusions}

Introducing the factor of exchange rate into the study of decision-making of enterprises in assembly supply chain, we set up a game model and obtain the equilibrium solution of enterprises. The conclusions obtained are as follow: the manufacture's optimal order quantity and every company's revenue will increase with the increase of expected exchange rate. These illustrate that manufacture should increase quantity of order if successfully forecast the raise of exchange rate ,and all the enterprises in the supply chain will benefit from the behavior .

\section{References}

[1] D. Ni ,J.Fang ,X.Tang, "Transmission Analysis of Demand and Exchange Rate risk in the supply chain," Journal of Industrial Engineering and Engi- neering Management, 27(1),pp. 49-55, 2013.

[2] H. Gurnania, Y. Gerchak, "Coordination in Decentralized Assembly Systems with Uncertain Component Yields," Eur. J. Oper. Res., 176(3), pp. 1559-1576, 2007.

[3] G. Yang, "Coordination Mechanism of Supply Chain Management Research Based on the Exchange Risk," Logistics Sci-Tech,10,pp. 8 10, 2012.

[4] Kouvelis P, Axarloglou K,Sinhav, "Exchange rates and choice of ownship structure of production facilities," management science, 48(8), pp. 1063-1080, 2001.

[5] L. Ma, Z.Shen, "Analyses of decision-making for exchange rate risk in supply chain management of small and medium-size eterprises," Journal of Dalian University of Technology,25(2),pp.51-60,2004.

[6] Shapiro J F, "Modeling the supply chain" Thomsin learning press, 2005.

[7] Y. Wang, "Joint Pricing-Production Decisions in Supply Chains of Complementary Products with Uncertain Demand". Oper. Res., 54(6), pp. 1110-1127, 2006

[8] Z.Zhao,'International supply chain contract with Quantity Discounts Taking Exchange rate Changing and Transportation Cost Sharing into Account," Chinese Jounal of Management Science,9(6),pp. 913-919,2012 